\title{
An Urban Supply Chain Distribution Model
}

\author{
Cristian Giovanny Gómez-Marín ${ }^{1}$, Julian Andres Zapata-Cortes ${ }^{2 *}$, \\ Martín Dario Arango-Serna ${ }^{1}$, Conrado Augusto Serna-Uran ${ }^{3}$ \\ ${ }^{1}$ Universidad Nacional de Colombia - Sede Medellín, Medellín, Colombia \\ ${ }^{2}$ Institución Universitaria CEIPA, Sabaneta, Antioquia, Colombia \\ ${ }^{3}$ Universidad de San Buenaventura - Seccional Medellín, Medellín, Colombia \\ crggomezma@unal.edu.co; julian.zapata@ceipa.edu.co; \\ mdarango@unal.edu.co; conrado.serna@usbmed.edu.co
}

\begin{abstract}
Increased activities in urban areas related with goods transportation lead companies to look for new strategies in order to develop those process in a more efficient way, aiming to reduce costs and increase customer's satisfaction. This paper presents an urban supply chain framework and a Mixed Integer Linear Programing Model for its optimization. The model uses different goods distribution actors, including several suppliers, one consolidation facility and several customers. The proposed framework and optimization model allow to generate optimal routes and the assignment of the customers and suppliers in the distribution network.
\end{abstract}

Keywords: distribution strategies, mixed integer linear programing, multiechelon distribution system, supply chain, urban goods distribution.

\section{Introduction}

In 2018 the people living in cities is around the $55 \%$ of the world's population and it is expected to increase to $68 \%$ by 2050 [1]. One of the most important issues to face in city planning and administration is the freight exchange to satisfy citizen's needs [2]. For that reasons, Urban Goods Distribution (UGD) is an important research field that impacts directly those key aspects, analyzing and proposing feasible solution that improve company competitiveness and people quality of life [3].

In order to propose solutions to organizing an efficient UGD, several elements must be considered, as for example the coordination and individual goals of the involved actors [4-6], the physical infrastructure, the economic vocation and the sustainability of the city, among others $[7,8]$. The cooperation and coordination among several actors is a key activity to generate proposals that improve the costs and customers service level in the UGD [10,11], both in the private and the public sectors [9].

According to Danielis et al. [12] and Tachizawa et al. [13] there is a need to research in urban goods distribution processes with the aim of understand how different configuration, actors and their behaviors, impact the network performance. Several

\footnotetext{
${ }^{*}$ Corresponding author.
} 
initiatives can be found in the literature to improve city goods distribution [9,14], in which coordination and collaboration between actor are highlighted as one of the more attractive initiatives to implement in Urban Goods Distribution [8]. Some research that integrate the coordination of multiple stakeholders, representing the diverse objective and behaviors could be founded in Nathanail [15], who realized that the cooperation among the actors is essential to obtain goods results of the operative. Bean and Joubert [16] analyzed the coordination between several actors, in this case considering the mutual interaction and responses of the carrier and customers, also finding improvements in the distribution performance. Liu et al [17] formulated a coordination strategy using two vehicles that can complement their planed routes, producing a decrease in the travel distance and optimizing the problem using a hybrid ant colony heuristic. Gutierrez et al [18] use a memetic algorithm to tackle the uncertainties in the routing problem improving the service and travel times. Aragao et al. [19] evaluated two different types of cooperative strategies (the use of additional auxiliary vehicles and negotiation between vehicles) to face the high degree of randomness presented in the urban freight distribution variables in a dynamic vehicle routing.

This paper presents a coordination model for the routing assignment optimization process in a two-echelon supply chain that consider suppliers, consolidation facilities and customers in the distribution process in the Hotel, restaurants and catering sector. In following section, the urban supply chain concept and some urban goods distribution strategies are provided by a literature review, followed by the urban supply chain model proposal. After that, the model is applied for several instances and the results are analyzed to finally present the conclusions and future research lines derived from the study.

\section{Urban Supply Chain (USC) and Goods Distribution Strategies}

The aims of Urban Supply Chain (USC) are to minimize the total cost of the pick-up and delivery process or maximize the benefits for the main actors, in most of the cases, without considering the sustainability of the supply chain [20,21], especially the social and environmental dimensions [11]. There are several goods distribution strategies in order to achieve those objectives, such as direct or multi-stop deliveries, or the use of one or several consolidation platforms in which products are consolidate to further deliveries to customers $[8,22]$. For the consolidation strategies it can be found several distribution networks, from which the most common are the Two tier [23, 24], the Multi-layer [25] and the Four-layer city distribution network [26, 27], which are depicted in figure 1 .

The two-tier city logistic system is based on a City Distribution Center (CDC) located on the edge of the urban zone and a set of satellites platforms that receives the goods form the CDC and deliver those to the customers using two types of vehicles, one to move the freight form CDC to satellites and other one to make the final delivery [23,12-32]. In the Multi-layer scheme, a first layer is dedicated to the suppliers, a second layer is dedicated to the CDC (or Hub) to coordinate the inbound and outbound 
flow of freight, and a third layer focused on the customers or the final distribution points $[3,25,33,34]$; The four layers' distribution strategy divided the geographic operation area into consolidation and deconsolidation zones. The first layer focused on transportation between supply points and consolidation centers (hubs), the second layer is dedicated to transport freight from hub to hub, the third layer is a deconsolidation zone at terminals or satellites facilities and the fourth layer is the delivery zone from terminals to final customers [26,27].

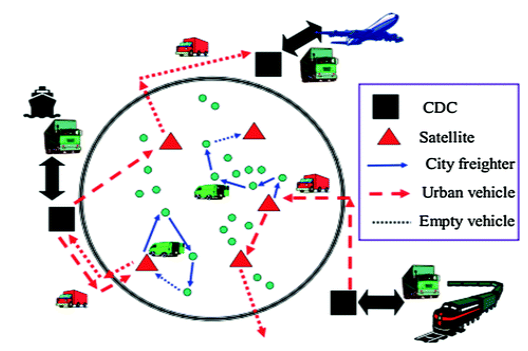

a. Two tier.

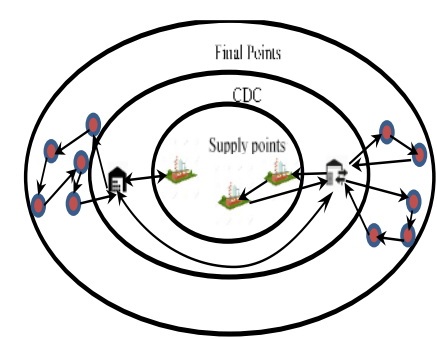

b. Multi-layer.

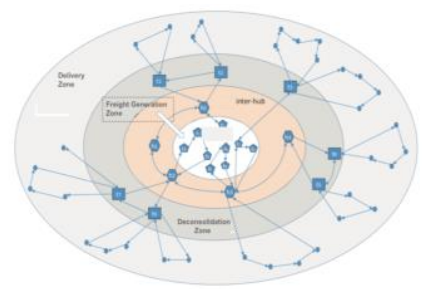

c. Four-layer.

Fig. 1. Most common city consolidation distribution system.

The strategies mentioned are used in the Urban Goods Distribution for different commercial and industrial sectors, where the retail sector is one of the most studied to perform and assess different strategies that improve the supply chain [35]. Other sector that can be analyzed under those distribution strategies is the Hotels, Restaurants and Catering distribution sector (Ho.Re.Ca) due to its similarities with the retailer sector, especially in the replenishment decision-making processes [35]. In the following section an integrative urban supply chain framework is proposed for the Ho.Re.Ca sector in which different distribution models can be analyzed.

\section{Urban Supply Chain Model for the Urban Goods Distribution}

In this section it is proposed an urban supply chain network for the Ho.Re.Ca sector, where multiple products should be delivered to the final consumption points [36] and three delivery alternatives are considered: a) direct deliveries from the producer to the final customer using an own fleet of vehicles, b) use of wholesalers (hub) for a specific geographic zone and d) use a combination of such alternatives. Normally, in this sector there are multiple suppliers and customers, logistics service providers and distribution 
centers (Hubs). The proposed model has three levels in which three different types of pick-up and delivery routes can be made:

Pick-up route - r1: This route is just dedicated to pick-up the products at supplier locations for the transportation to the consolidation center (hub).

Pick-up and delivery routes - r2: In this type of route both pick-up and delivery process are performed, first the pick-up from the supplier and then the delivery services are accomplished without consolidation at the hub. The hub could be a node to deliver goods.

Delivery Routes r3: In this type of routes goods deliveries from the hub are made to customers. These deliveries can be made directly or in tour way.

In this structure all vehicles must leave and arrive from the distribution center and each supplier produce only one type of product. This routes are depicted in figure 2.

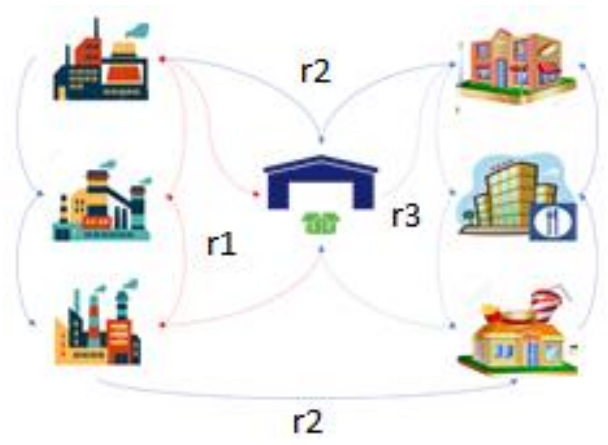

Fig. 2. Proposed Three level distribution network

\section{$4 \quad$ Model Formulation}

In order to define the mathematical model, a direct graph $G=(N, A)$ is considered, where $\mathrm{N}$ is the set of nodes $N=C \cup F \cup 0$ containing the subset $C:=\left\{j, \ldots, j^{\prime}\right\} \in \mathbb{N}$ that represent the customers, subset $F:=\left\{i, \ldots, i^{\prime}\right\} \in \mathbb{N}$ representing the suppliers and node 0 representing the hub (only one hub is consider in this case). The set of arcs A is the link between the nodes. There are complete subgraphs consisting of suppliers $i, \ldots, i^{\prime}$ and the hub 0 ; and customers $j, \ldots, j^{\prime}$ and the hub 0 . To ensure that there are direct transportation between suppliers and customers, $G$ contain $\operatorname{arcs}\{i, j\}, i \in F, j \in C$. The homogenous fleet of vehicles are indexed by $k \in K$ where $K \in \mathbb{N}$, and those start and finish their routes $R:\left\{r_{1}, r_{2}, r_{3}\right\}$ at the hub 0 .

To ensure that the hub behaves as a consolidation center, the route r1 must be executed before $\mathrm{r} 3$ allowing that the products that arrive to the hub in route one, can be processed for the distribution in further transports in route $r 3$.

The Objective Function that minimizes the transportation cost using mixed integer linear programming formulation (MILP) is presented in equation 1 and three groups of different constraints are considered (Common constraints for routing problems, constraints for vehicle flow conservation, constraints for capacity in each type of route $\mathrm{R})$. The constraints are presented in annex A. 


$$
\begin{aligned}
\operatorname{Min} \sum_{k \in K}\left[\sum_{i \in F} C_{0, i} x_{0, i}^{k, r_{1}}+\sum_{i \in F} \sum_{j \in F, i \neq j} C_{i, j} x_{i, j}^{k, r_{1}}+\sum_{i \in F} C_{i, 0} x_{i, 0}^{k, r_{1}}\right] \\
+\sum_{k=1}^{K}\left[\sum_{i=1}^{F} C_{0, i} x_{0, i}^{k, r_{2}}+\sum_{i}^{F} \sum_{j, i \neq j}^{F} C_{i, j} x_{i, j}^{k, r_{2}}+\sum_{i}^{F} \sum_{j}^{C} C_{i, j} x_{i, j}^{k, r_{2}}\right. \\
\left.+\sum_{i}^{C} \sum_{j, i \neq j}^{C} C_{i, j} x_{i, j}^{k, r_{2}}+\sum_{i}^{C} C_{i, 0} x_{i, 0}^{k, r_{2}}\right] \\
+\sum_{k=1}^{K}\left[\sum_{j=1}^{C} C_{0, j} x_{0, j}^{k, r_{3}}+\sum_{i}^{C} \sum_{j, i \neq j}^{C} C_{i, j} x_{i, j}^{k, r_{3}}+\sum_{i=1}^{C} C_{i, 0} x_{i, 0}^{k, r_{3}}\right] .
\end{aligned}
$$

The model notation for parameters and variables is:

$\mathrm{K}=\{\mathrm{k}\}$ Set of vehicles.

$C^{k} \quad$ Capacity of the vehicle $k \in K$.

$d_{j, p} \quad$ Demand form the customer $\mathrm{j} \in \mathrm{C}$ of product $\mathrm{p} \in \mathrm{P}$.

$o_{i, p} \quad$ Quantity of product $\mathrm{p} \in \mathrm{P}$ supplied by supplier $\mathrm{i} \in \mathrm{F}$.

$\lambda_{i}^{k} \quad$ Time when the vehicle $\mathrm{k} \in \mathrm{K}$ begins it service to the customer $\mathrm{j} \in \mathrm{C}$.

$u_{j} \quad$ service time duration at customer $j \in C$.

$e_{j}, l_{j} \quad$ Time window for the service at customer $\mathrm{j} \in \mathrm{C}$.

$t_{i j}^{k} \quad$ Travel time of vehicle $\mathrm{k} \in \mathrm{K}$ between the nodes $\mathrm{i}, \mathrm{j} \in \mathrm{N}$.

$q_{i, p}^{k, r} \quad$ quantity of product $\mathrm{p} \in \mathrm{P}$ transported in the vehicle $\mathrm{k} \in \mathrm{K}$ before visit the node $i \in\{F \cup 0 \cup C\}$ on the route $r \in\{R\}$.

$\rho_{j, p}^{k} \quad$ Quantity of product $\mathrm{p} \in \mathrm{P}$ in the vehicle $\mathrm{k} \in \mathrm{K}$ that leave the hub and must be delivered at the nodes $\mathrm{j} \in \mathrm{C}$.

$x_{i j}^{k r} \quad$ Decision binary variable, 1 if the vehicle $k \in K$ uses the arc from $\mathrm{i}$ to $\mathrm{j}$ in the route $r \in R$, otherwise 0 .

\section{$5 \quad$ Discussion and Analysis of Results}

To solve the problem presented in the former section in an exact way, the model was formulated on GAMS (General Algebraic Modeling System software) and solved using Mixed Integer Linear Programing (MILP) in the CPLEX Solver. For testing the model, five small and medium instances were randomly generated, considering less suppliers than customers like in real applications. The network configuration for the test instances and the cost obtained with the model are presented in Table 1, in all cases using a single hub, several suppliers and customers.

For the instances 1 and 2, with six and eight nodes respectively, the better routes to perform are route 2 (pick-up and delivery route). For the instance 3 with 10 nodes, the routes two and three are used for accomplishing the service to all the customers. The same occurs for instances 4 and 5 with 12 and 14 nodes respectively, in which routes two and three are generated as presented in Table 2. Figure 3 depicts the routes between suppliers, customers and the Hub for the instance 5 with 14 nodes at a Cartesian plane 
Cristian Giovanny Gómez-Marín, Julian Andres Zapata-Cortes, Martín Dario Arango-Serna, et al.

that allows to obtain Euclidian distances and generate the routes construction according to the MILP optimization model.

Table 1. Instance configuration

\begin{tabular}{cccc}
\hline Instance & Configuration $(\mathrm{F}-0-\mathrm{C})^{*}$ & \# nodes & Cost \\
\hline 1 & $2-1-3$ & 6 & 244 \\
2 & $2-1-5$ & 8 & 318 \\
3 & $3-1-6$ & 10 & 470 \\
4 & $3-1-8$ & 12 & 493 \\
5 & $3-1-10$ & 14 & 494 \\
\hline
\end{tabular}

* notation used in the model formulation (F: suppliers, 0: Hub, C: customers)

Table 2. Tour and routes for the instances.

\begin{tabular}{clcl}
\hline Instance & \multicolumn{1}{c}{ Tour } & Route & Distance \\
\hline 1 & $0-\mathrm{F} 1-\mathrm{F} 2-\mathrm{C} 1-\mathrm{C} 2-\mathrm{C} 3-0$ & $\mathrm{r} 2$ & 244 \\
2 & $0-\mathrm{F} 1-\mathrm{F} 2-\mathrm{C} 1-\mathrm{C} 5-\mathrm{C} 4-\mathrm{C} 3-\mathrm{C} 5-0$ & $\mathrm{r} 2$ & 318 \\
3 & $0-\mathrm{F} 3-\mathrm{F} 2-\mathrm{F} 1-\mathrm{C} 6-\mathrm{C} 5-\mathrm{C} 1-0$. & $\mathrm{r} 2$ & 228 \\
& $0-\mathrm{C} 4-\mathrm{C} 3-\mathrm{C} 2-0$ & $\mathrm{r} 3$ & 242 \\
4 & $0-\mathrm{F} 1-\mathrm{F} 2-\mathrm{F} 3-\mathrm{C} 6-\mathrm{C} 5-\mathrm{C} 1-0$ & $\mathrm{r} 2$ & 228 \\
& $0-\mathrm{C} 2-\mathrm{C} 3-\mathrm{C} 4-\mathrm{C} 7-\mathrm{C} 8-0$ & $\mathrm{r} 3$ & 265 \\
5 & $0-\mathrm{F} 3-\mathrm{F} 2-\mathrm{F} 1-\mathrm{C} 6-\mathrm{C} 9-\mathrm{C} 5-\mathrm{C} 1-0$ & $\mathrm{r} 2$ & 228 \\
& $0-\mathrm{C} 2-\mathrm{C} 3-\mathrm{C} 4-\mathrm{C} 7-\mathrm{C} 8-\mathrm{C} 10-0$ & $\mathrm{r} 3$ & 266 \\
\hline
\end{tabular}

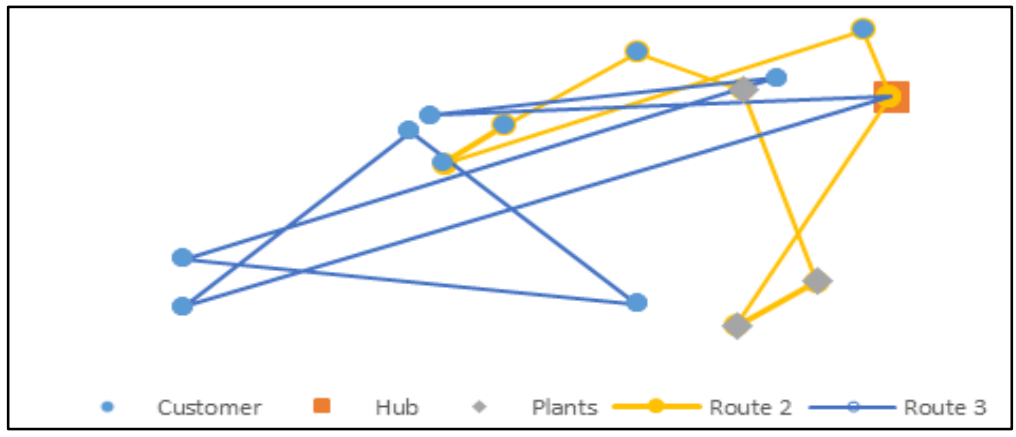

Fig. 3. Routes generated for the instance 5 .

From table 2 it can be observed that the greater the number of nodes, the greater the total travel distance. Also, when there are few nodes just one route is activated. As the number of nodes increases, new routes are activated to divide the travel distance and equilibrate the loads.

When the instances include more than 15 nodes "the dimensionality curse" has their effect and the computation time and the computational memory use increases significantly, and the solver does not find a feasible solution in a reasonable 
computational time, so for larger instances the problem must be solved using a more robust and fast computer which increase computational calculation cost, reason of why it is suggested the use of metaheuristic methods, such as genetic algorithms or Tabu search for techniques based on population and trajectory respectively [37].

\section{Conclusions}

Urban fright distribution includes several actors and transportation levels that must be consider in order to model and solve problems according to real conditions. Different strategies have been used in urban supply chain for the Urban Goods Distribution processes, in which is difficult to assign routes and vehicles to the facilities involved in the transport/distribution process. This article presented a Mixed Integer Linear Programming (MILP) model that allows configure the routes and the facility assignments to such routes for small and medium instances, that can be solved exactly for distribution network involving one hub and several suppliers and customers.

The results obtained for the model in the tested instances allows conclude about the ability of the model to obtain solution for a very common distribution problem in the Ho.Re.Ca sector. The behavior of the model is according to what was expected for the solutions of the tested instances. In this way, when solving small problems, a single route is required, but when bigger instances have to be solved, several routes and a more complex distribution plans are generated by the MILP model. However, when the proposed model has to solve instances with more than 14 nodes, the computational time and the memory requirements increase significantly, reason of why it is suggested the use of metaheuristics methods to solve those problems.

As future research lines, it is suggested to develop metaheuristics methods for solving the model in order to analyze complex distribution networks with more suppliers, hubs and customers. It is also interesting to incorporate more variables and conditions in the urban distribution model, such as traffic congestion and time windows. Another future research line is the use of multi-agent systems for asses the different behaviors and the response levels to dynamic changes in operational conditions, such as travel time, service time and dynamic demands.

\section{References}

1. United Nations Department of Economic and Social Affairs: World Urbanization Prospects: The 2018 Revision - Press release. Available in: https://population.un.org/wup/Publications/. Last Visited: September 1 of 2018 (2018)

2. Ros-McDonnell, L.R., De-la-Fuente-Aragón, M.V., Ros-McDonnell, D., Cardós, M.: Analysis of freight distribution flows in an urban functional area. Cities, Volume 79, pp 159$168(2018)$

3. Arango-Serna, M.D., Serna-Uran, C.A., Zapata-Cortes, J.A.: Multi-agent System Modeling for the Coordination of Processes of Distribution of Goods Using a Memetic Algorithm. In: García-Alcaraz J., Alor-Hernández G., Maldonado-Macías A., Sánchez-Ramírez C. (eds) New Perspectives on Applied Industrial Tools and Techniques. Management and Industrial Engineering. Springer, Cham (2018) 
4. Arango, M.D., Zapata, J.A., Gutierrez, D.: Modeling The Inventory Routing Problem (IRP) With Multiple Depots with Genetic Algorithms. IEEE Latin American Transactions 13(12): 3959- 965 (2015)

5. Arango-Serna, M.D., Zapata-Corte,s J.A., Serna-Uran, C.A.: Collaborative Multiobjective Model for Urban Goods Distribution Optimization. In: García-Alcaraz J., Alor-Hernández G., Maldonado-Macías A., Sánchez-Ramírez C. (eds) New Perspectives on Applied Industrial Tools and Techniques. Management and Industrial Engineering. Springer, Cham (2018)

6. Arango, M.D., Zapata, J.A.: Multiobjective Model for The Simultaneous Optimization of Transportation Costs, Inventory Costs and Service Level in Goods Distribution. EEE Latin america Transactions 15(1), pp. 129-136 (2017)

7. Arango-Serna, M.D., Gómez-Marín, C.G., Serna-Urán, C.A.: Modelos logísticos aplicados a la distribución urbana de mercancías. Revista EIA 14(28), pp .57-76 (2017)

8. Zapata-Cortes, J.A.: Optimización de la distribución de mercancías utilizando un modelo genético multiobjetivo de inventario colaborativo de $\mathrm{m}$ proveedores con $\mathrm{n}$ clientes. Tesis Doctoral, Universidad Nacional de Colombia (2016)

9. Muñuzuri, J.: La logística urbana de mercancías: Soluciones, modelado y Evaluación. Doctor Ingeniero Industrial, Universidad de Sevilla, Sevilla. España (2003)

10. Febbraro, A., Di-Sacco, N., Saeednia, M.: An agent-based framework for cooperative planning of intermodal freight transport chains. Transportation Research Part C, 64, pp.7285. Available at: https://ac-els-cdn-com.ezproxy.unal.edu.co/S0968090X15004301/1-s2.0S0968090X15004301-main.pdf?_tid=spdf-1e85e57d-447d-4545-a6fad476dd10b5ef\&acdnat=1518811138_c7cf8c8b75494658b8580d9737653630 [Accessed February 16, 2018] (2016)

11. Österle, I., Aditjandra, P.T., Vaghi, C., Grea, G., Zunder, T.H.: The role of a structured stakeholder consultation process within the establishment of a sustainable urban supply chain. Supply Chain Management: An International Journal 20(3), pp. 284-299. Available at: https://doi.org/10.1108/SCM-05-2014-0149 [Accessed May 15, 2018] (2015)

12. Danielis, R., Maggi, E., Rotaris, L.,.Valer, E.: Urban freight distribution: Urban supply chains and transportation Policies. In M. Ben-Akiva, H. Meersman, \& E. Van de Voorde (eds). Freight Transport Modeling. Emerald Group Publishing Limited, pp. 377-403 (2013)

13. Tachizawa, E.M., Alvarez-Gil, M.J., Montes-Sancho, M.J.: How "smart cities" will change supply chain management. Supply Chain Managment: An International Journal 20(4): $237-$ 248. Available at: https://doi.org/10.1108/SCM-03-2014-0108 [Accessed May 15, 2018] (2015)

14. Zenezini, G., De-Marco, A.: A review of methodologies to assess urban freight initiatives. IFAC-PapersOnLine, Volume 49, Issue 12, 2016, pp 1359-1364 (2018)

15. Nathanail, E.: A Multistakeholders Multicriteria Decision Support Platform for Assessing Urban Freight Transport Measures. In: Kabashkin, I., Yatskiv, I., and Prentkovskis, O. (eds.) Reliability and Statistics in Transportation and Communication. Lecture Notes in Networks and Systems, pp. 17-31. Springer International Publishing. Riga, Latvia (2018)

16. Bean, W.L., Joubert, J.W.: A systematic evaluation of freight carrier response to receiver reordering behaviour. Computers and Industrial Engineering 124, pp. 207-219 (2018)

17. Liu, C.S., Kuo, G., Huang, F.H.: Vehicle coordinated strategy for vehicle routing problem with fuzzy demands. Mathematical Problems in Engineering, pp. 1-10 (2016)

18. Gutierrez, A., Dieulle, L., Labadie, N., Velasco, N.: A multi-population algorithm to solve the VRP with stochastic service and travel times. Computers \& Industrial Engineering 125, pp. 144-156 (2018) 
19. Aragão, D.P., Galvão-Novaes, A., Mendes-Luna, M.M.: An agent-based approach to enable dynamic vehicle routing in milk-run OEM operations. In: XXVIII Congreso de Pesquisa e Ensino em Transportes. Curitiba (2016)

20. Jadhav, A., Orr, S., Malik, M.: The role of supply chain orientation in achieving supply chain sustainability. International Journal of Production Economics (2018)

21. Morais, D.O.C., Silvestre, B.S.: Advancing social sustainability in supply chain management: Lessons from multiple case studies in an emerging economy. Journal of Cleaner Production 199, pp. 222-235 (2018)

22. Rushton, A., Croucher, P., Baker, P.: The handbook of logistics and distribution management: Understanding the supply chain. 5th edition. Ed. Kogan Page Limited. ISBN 0749466278 (2014)

23. Crainic, T.G., Ricciardi, N., Storchi, G.: Models for evaluating and planning city logistics systems. Transportation Science 43(4), pp. 432-454 (2007)

24. Zhou, L., Baldacci, R., Vigo, D., Wang, X.: A Multi-Depot Two-Echelon Vehicle Routing Problem with Delivery Options Arising in the Last Mile Distribution. European Journal of Operational Research 265(2), pp. 765-778 (2018)

25. Lu, C.C., Ying, K.C., Chen, H.J.: Real-time relief distribution in the aftermath of disasters A rolling horizon approach. Transportation Research Part E: Logistics and Transportation Review, 93, pp. 1-20. Available at: http://dx.doi.org/10.1016/j.tre.2016.05.002 (2016)

26. Serna-Uran, C.A.: Modelo multi-agente para problemas de recogida y entrega de mercancías con ventanas de tiempo usando un algoritmo memético con relajaciones difusas. Universidad Nacional de Colombia (2016)

27. Rieck, J., Ehrenberg, C., Zimmermann, J.: Many-to-many location-routing with inter-hub transport and multi-commodity pickup-and-delivery. European Journal of Operational Research 236(3), pp. 863-878. Available at: http://dx.doi.org/10.1016/j.ejor.2013.12.021 (2014)

28. Hemmelmayr, V.C., Cordeau, J.F., Crainic, T.G.: An adaptive large neighborhood search heuristic for Two-Echelon Vehicle Routing Problems arising in city logistics. Computers \& Operations Research 39(12), pp. 3215-3228 (2012)

29. Amaral, R.R., Aghezzaf, E.H.: City Logistics and Traffic Management: Modelling the Inner and Outer Urban Transport Flows in a Two-tiered System. Transportation Research Procedia (2015)

30. Faccio, M., Gamberi, M.: New City Logistics Paradigm: From the "Last Mile" to the "Last 50 Miles" Sustainable Distribution. Sustainability (7)11, pp. 1-22 (2015)

31. Nguyen, V.P., Prins, C., Prodhon, C.: Solving the two-echelon location routing problem by a GRASP reinforced by a learning process and path relinking. European Journal of Operational Research, 216(1), pp.113-126. Available at: http://dx.doi.org/10.1016/j.ejor.2011.07.030 (2012)

32. Arango-Serna, M.D., Serna-Uran, C.A., Zapata-Cortes, J.A., Alvarez, A.F.: Vehicle routing to multiple warehouses using a memetic algorithm. Procedia - Social and Behavioral Sciences, 160(Cit), pp. 587-596. http://doi.org/10.1016/j.sbspro.2014.12.172 (2014)

33. Crainic, T.G., Montreuil, B.: Physical Internet Enabled Interconnected City Logistics. Available at: https://www.cirrelt.ca/DocumentsTravail/CIRRELT-2015-13.pdf [Accessed September 22, 2017] (2015)

34. Novaes, A.G.N., Bez, E.T. Burin, P.J., AragãoJr, D.P.: Dynamic milk-run OEM operations in over-congested traffic conditions. Computers and Industrial Engineering 88, pp. 326-340 Available at: http://dx.doi.org/10.1016/j.cie.2015.07.010 (2015)

35. Russo, F., Comi, A.: A model for simulating urban goods transport and logistics: The integrated choice of ho.re.ca. activity decision-making and final business consumers. 
Cristian Giovanny Gómez-Marín, Julian Andres Zapata-Cortes, Martín Dario Arango-Serna, et al.

Procedia - Social and Behavioral Sciences, 80(Isttt), pp. 717-728. Available at: http://linkinghub.elsevier.com/retrieve/pii/S1877042813010070 (2013)

36. Ponce-Cueto, E., Carrasco-Gallego, R., García-García, R.: Propuesta de una guía de selección del modelo de distribución en el sistema logístico del canal HORECA. Dirección y Organización, $000(37), \quad$ pp. 67-75. Available at: http://www.revistadyo.com/index.php/dyo/article/view/40 (2009)

37. Arango, M.D., Zapata, J.A., Andres, C.: Metaheuristics for goods distribution. Proceedings of 2015 International Conference on Industrial Engineering and Systems Management (IESM), IEEE Publications. pp. 99 - 107. DOI. 10.1109/IESM.2015.7380143 (2015) 